\title{
Cấu trúc kỳ hạn nọ̣ của các công ty kinh doanh bất động sản niêm yết trên thị trường chứng khoán Việt Nam
}

\section{Debt manturity structure of real estate firms on Vietnam exchange stock}

\author{
Phạm Thị Vân Trinh ${ }^{1 *}$ \\ ${ }^{1}$ Trường Cao đẳng Kinh tế - Kỹ thuật Thành phố Hồ Chí Minh, Việt Nam \\ *Tác giả liên hệ, Email: baotrinh77@ yahoo.com.vn
}

THÔNG TIN

DOI: $10.46223 / \mathrm{HCMCOUJS.}$

econ.vi.13.1.527.2018

Ngày nhận: 19/09/2017

Ngày nhận lại: 24/11/2017

Duyệt đăng: 20/12/2017

Tù̀ khóa:

cấu trúc kỳ hạn nợ, FEM, REM, pooled OLS, SysGMM

Keywords:

debt manurity structure, FEM, pooled OLS, REM, Sys-GMM

\section{TÓM TẮT}

Bài viết là một nghiên cứu thực nghiệm về các nhân tố ảnh hưởng đến cấu trúc kỳ hạn nợ của các công ty kinh doanh bất động sản niêm yết trên thị trường chứng khoán Việt Nam. Tác giả thu thập các báo cáo tài chính đã được kiểm toán của 67 công ty kinh doanh bất động sản niêm yết trên thị trường chứng khoán Việt Nam trong giai đoạn từ năm 2010 đến 2016. Với việc sử dụng mô hình Sys-GMM, kết quả nghiên cứu chỉ ra rằng đòn bẩy tài chính, quy mô công ty, cơ cấu tài sản, khả năng thanh toán, biến động lợi nhuận là những yếu tố tác động cấu trúc kỳ hạn nợ của doanh nghiệp, các yếu tố khác như cơ hội tăng trưởng, thuế thu nhập doanh nghiệp không có ý nghĩa thống kê.

\begin{abstract}
The article is an empirical study of the factors affecting the debt maturity structure of real estate companies listed on Vietnam's stock market. The author collects audited financial statements of 67 listed real estate companies listed on Vietnam's stock market for the period from 2010 to 2016. With the use of the Sys-GMM model, the results of the research indicate that financial leverage, company size, asset structure, solvency, profit margins are factors that influence the firm's debt maturity structure, other factors such as growth opportunities, and corporate income tax are not statistically significant.
\end{abstract}

\section{Giới thiệu}

Bất kỳ một doanh nghiệp nào muốn hoạt động thì cần phải có vốn. Nguồn vốn này được hình thành từ vốn góp của cổ đông và từ nợ đi vay. Như vậy, việc quyết định lựa chọn vốn từ vay nợ sẽ tùy thuộc vào kỳ hạn nợ vì nợ được khấu trừ thuế và đại diện cho nguồn tài chính rẻ hơn so với vốn chủ sở hữu. Nợ là một khía cạnh quan trọng của tài chính và là công cụ kiểm 
soát những bất lợi và tăng lợi thế trong việc lựa chọn nợ ngắn hạn và nợ dài hạn. Kỳ hạn nợ là kỳ hạn phải trả cho các khoản nợ ngắn hạn và nợ dài dạn. Quyết định lựa chọn một kỳ hạn nợ tối ưu sẽ giúp cho doanh nghiệp có nhiều cơ hội, giảm thiểu các rủi ro từ các nguồn tài trợ, tăng tính minh bạch và khai thác các cơ hội từ việc khấu trừ thuế do nợ vay.

Các công trình nghiên cứu trên thế giới sử dụng các lý thuyết cấu trúc vốn hiện đại để kiểm chứng và giải thích vì sao các doanh nghiệp lựa chọn cấu trúc kỳ hạn nợ. Hầu hết nghiên cứu về cấu trúc kỳ hạn nợ tập trung ở những nước phát triển như nghiên cứu của Brick và Ravid (1985), Stohs và Mauer (1996), (Stephan, Talavera, \& Tsapin, 2011) và gần đây lan rộng sang các nước có nền kinh tế mới nổi như nghiên cứu của Cai, Fairchild, và Guney (2008), Deesomsak, Paudyal, và Pescetto (2009), Terra (2011), Stephan và cộng sự (2011), Lemma và Negash (2012). Các nghiên cứu này dựa trên các lý thuyết hiện đại về cấu trúc vốn giải thích các yếu tố liên quan đến thuế, thông tin bất cân xứng, chi phí đại diện có tác động đến cấu trúc kỳ hạn nợ. Tuy nhiên, các nghiên cứu các yếu tố ảnh hưởng đến cấu trúc kỳ hạn nợ ở các doanh nhiệp tại Việt Nam còn hạn chế, đặc biệt là các doanh nghiệp kinh doanh bất động sản. Vì vậy, mục đích của bài viết này là phân tích các nhân tố ảnh hưởng đến cấu trúc kỳ hạn nợ của các doanh nghiệp kinh doanh bất động sản Việt Nam niêm yết trên thị trường chứng khoán Việt Nam giai đoạn từ 2010 đến 2016.

\section{Tổng quan lý thuyết và các nghiên cứu thực nghiệm về cấu trúc kỳ hạn nọ̣}

\subsection{Các lý thuyết về cấu trúc kỳ hạn nơ}

Lý thuyết cân bằng (Trade Off Theory - TOT), Myers (1977) cho rằng việc lựa chọn kỳ hạn nợ tối ưu thì doanh nghiệp phải xem xét đến chi phí đại diện trên cơ sở thông tin bất cân xứng. Theo quan điểm của lý thuyết cân bằng, sự cân bằng giữa chi phí nợ ngắn hạn do đi vay với lãi suất cao hơn so với nợ dài dạn để tái đầu tư nếu giả định có sự tồn tại kỳ hạn nợ tối ưu, chi phí giao dịch khác nhau với các khoản nợ khác nhau như chi phí phát hành, lợi ích từ lá chắn thuế, chi phí phá sản. Flannery (1986) cho rằng các công ty có nguồn tài chính tốt thích nợ ngắn hạn do khả năng dự báo được sức khỏe tài chính, còn Diamond và Rajan (2001) cho rằng công ty có nguồn tài chính kém sẽ chấp nhận rủi ro thanh khoản khi sử dụng nợ ngắn hạn, thay vì phát hành nợ dài hạn do các công ty này bị đánh giá dựa trên thông tin bất cân xứng.

Lý thuyết chi phí đại diện (Agency Cost), chi phí đại diện của vốn chủ sở hữu phát sinh do bất cân xứng thông tin giữa người quản lý công ty và chủ sở hữu doanh nghiệp, giữa các cổ đông và người điều hành công ty, giữa cổ đông lớn và cổ đông thiểu số. Để giảm chi phí đại diện, doanh nghiệp có xu hướng tăng sử dụng nợ vay. Trong đó, vấn đề đại diện của nợ xảy ra hai trường hợp có thể làm cho chi phí đại diện ngày càng tăng do "đầu tư dưới mức" hoặc "đầu tư quá mức". Myers (1977) cho rằng việc sử dụng nợ ngắn hạn sẽ làm giảm bớt việc "đầu tư dưới mức" khi các doanh nghiệp không muốn theo đuổi những dự án có rủi ro, điều này sẽ làm giảm chi phí đại diện thông qua cơ chế giám sát thường xuyên từ nhà đầu tư. Như vậy, nợ ngắn hạn được sử dụng để tài trợ cho tài sản ngắn hạn và nợ dài hạn tài trợ cho tài sản dài hạn, do vậy việc sử dụng kỳ hạn nợ hợp lý sẽ giảm thiểu xung đột và mâu thuẫn giữa cổ đông và trái chủ, vì vậy các công ty có quy mô nhỏ thường phải chịu chi phí đại diện cao hơn do khả năng chuyển dịch rủi ro từ mâu thuẫn đại diện giữa người quản lý và cổ đông càng lớn. Bên cạnh đó, chi phí đại diện có thể kiểm soát được nợ ngắn hạn (Barnea, Haugen, \& Senbet, 1980). Tuy 
nhiên, Demirgüç-Kunt và Vojislav (1999) cho rằng các doanh nghiệp có tình hình tài chính tốt thì cần phải phát triển các nguồn lực bên trong và cố gắng giảm các kỳ hạn nợ để giải quyết mâu thuẫn giữa các bên có liên quan.

Lý thuyết tín hiệu (Signalling Theory) được đề xuất bởi Jensen và Meckling (1976) dựa trên bất cân xứng thông tin và được Myers (1977) phát triển. Cấu trúc kỳ hạn nợ được xem là công cụ để giải quyết mâu thuẫn đại diện, các doanh nghiệp phải đưa ra tín hiệu về tình hình tài chính hiện tại nhằm đảm bảo khả năng trả nợ. Những tín hiệu từ thông tin bất cân xứng hàm ý các doanh nghiệp lựa chọn kỳ hạn nợ như là việc phát tín hiệu cho thị trường và người quản lý luôn có thông tin tốt hơn so với các nhà đầu tư bên ngoài về tình hình sức khỏe tài chính của doanh nghiệp. Việc phát hành nợ ngắn hạn cho thấy doanh nghiệp có được tín hiệu tốt về tình hình tài chính của doanh nghiệp (Diamond \& Rajan, 2001; Flannery, 1986), biến động thu nhập (Stohs \& Mauer, 1996). Trong trường hợp có khoảng cách về bất cân xứng thông tin giữa người huy động và người tài trợ, công ty sẽ sử dụng tài sản có tính thanh khoản cao thay vì sử dụng nợ hoặc vốn chủ sở hữu (Myers \& Majluf, 1984). Mặt khác, doanh nghiệp có tài chính tốt sẽ sử dụng nhiều nợ ngắn hạn hơn khi họ kiểm soát được rủi ro tài chính và rủi ro lãi suất của nợ vay ngắn hạn (Jun \& Jen, 2003).

Lý thuyết về thuế, Brick và Ravid (1985) giải thích rằng thuế có mối quan hệ trong việc lựa chọn giữa nợ ngắn hạn và nợ dài hạn, các doanh nghiệp cấu trúc kỳ hạn nợ tối ưu là sự đánh đổi giữa lợi ích từ lá chắn thuế cho các khoản nợ của doanh nghiệp và những bất lợi từ chi phí đại diện. Công ty sử dụng nhiều nợ dài hạn khi cấu trúc kỳ hạn của lãi suất có hệ số góc dương vì các khoản chi phí sẽ gia tăng khi đó sẽ tiết kiệm nhiều từ lá chắn thuế (khuyến khích doanh nghiệp vay) và công ty sẽ có lợi nhuận nhiều hơn. Brick và Ravid (1991) tiếp tục thể hiện sự tối ưu của nợ dài hạn khi cấu trúc kỳ hạn của lãi suất có hệ số góc âm hoặc bằng không. Stohs và Mauer (1996), cũng tìm thấy một số tác động tích cực từ thuế do sử dụng nợ dài hạn. Cấu trúc kỳ hạn của lãi suất giảm thì các công ty sẽ quyết định lựa chọn nợ dài hạn. Mặt khác, Lewis (1990) cho rằng thuế sẽ không tác động đến giá trị doanh nghiệp khi mà cấu trúc vốn mục tiêu và cấu trúc kỳ hạn nợ được xác định tại một thời điểm nhất định.

\subsection{Các nghiên cứu thục nghiệm}

Deesomsak và cộng sự (2009), xác định các yếu tố tác động đến cấu trúc kỳ hạn nợ của các công ty tại Thái Lan, Malaysia, Singapore và Úc. Kết quả tìm thấy bằng chứng quy mô công ty, tỷ lệ nợ và tính thanh khoản có tác động dương đến kỳ hạn nợ; các yếu tố gồm lợi nhuận, kỳ hạn tài sản, biến động thu nhập có tác động khác nhau ở những quốc gia khác nhau. Riêng yếu tố cơ hội tăng trưởng không có ý nghĩa trong mô hình nghiên cứu.

Cai và cộng sự (2008), nghiên cứu các yếu tố quyết định kỳ nạn nợ của các công ty niêm yết trên sàn chứng khoán ở Trung Quốc. Kết quả nghiên cứu cho thấy quy mô của công ty, kỳ hạn tài sản và thanh khoản có tác động đáng kể đến kỳ hạn nợ. Yếu tố tài sản hữu hình và cơ hội tăng trưởng có ảnh hưởng tích cực đến kỳ hạn nợ, ngược lại biến đại diện cho mức tín nhiệm của công ty và biến thuế suất doanh nghiệp cho kết quả không rõ ràng hoặc không có ảnh hưởng đến kỳ hạn nợ như kỳ vọng.

Terra (2011), nghiên cứu các nhân tố tác động đến cấu trúc kỳ hạn nợ của các công ty niêm yết tại Mỹ và các nước thuộc Mỹ Latinh. Kết quả cho thấy kỳ hạn nợ giữa các công ty niêm yết tại Mỹ và các nước thuộc Mỹ Latinh là tương tự nhau mặc dù có sự khác biệt về môi 
trường tài chính và môi trường kinh doanh giữa các quốc gia trong mẫu khảo sát. Các yếu tố tác động cùng chiều với kỳ hạn nợ gồm tỷ lệ nợ, kỳ hạn tài sản, tính thanh khoản; thuế, cơ hội tăng trưởng có tác động ngược chiều đến kỳ hạn nợ; còn lại yếu tố quy mô công ty, lợi nhuận, tài sản hữu hình không có ảnh hưởng đến kỳ hạn nợ.

Stephan và cộng sự (2011), nghiên cứu các yếu tố quyết định cấu trúc kỳ hạn nợ tại các thị trường mới nổi với dữ liệu bảng của 4.500 công ty Ukraine trong giai đoạn 2000-2006. Kết quả thực nghiệm khẳng định tầm quan trọng của các lý thuyết chi phí đại diện, thanh khoản, phát tín hiệu và thuế đối với cấu trúc kỳ hạn nợ.

Lemma và Negash (2012), nghiên cứu cấu trúc kỳ hạn nợ của các công ty niêm yết thuộc các quốc gia ở châu Phi. Kết quả nghiên cứu cho thấy có hai nhóm nhân tố nội tại (bên trong doanh nghiệp) và nhóm yếu tố bên ngoài có tác động đến cấu trúc kỳ hạn nợ. Nhóm các yếu tố nội tại tác động dương đến cấu trúc kỳ hạn nợ gồm kỳ hạn tài sản, biến động thu nhập, tỷ lệ nợ. Nhóm các yếu tố bên ngoài tác động không rõ ràng gồm thuế, tăng trưởng nền kinh tế.

Trên cơ sở lý thuyết và các nghiên cứu thực nghiệm trên thế giới trong thời gian qua cho thấy cấu trúc kỳ hạn nợ chịu tác động bởi nhiều yếu tố khác nhau ở những quốc gia khác nhau, chủ yếu nghiên cứu thực nghiệm ở những quốc gia phát triển có điều kiện kinh tế khác nhau. Đối với Việt Nam, nghiên cứu thực nghiệm các yếu tố tác động đến cấu trúc kỳ hạn nợ của các doanh nghiệp thuộc lĩnh vực bất động sản tương đối ít. Đây chính là cơ sở để tác giả nghiên cứu các yếu tố tác động đến cấu trúc kỳ hạn nợ của các công ty kinh doanh bất động sản niêm yết ở Việt Nam.

\section{Dữ liệu và phương pháp nghiên cứu}

\subsection{Mô tả dũ liệu nghiên cúu}

Dữ liệu nghiên cứu gồm 67 doanh nghiệp kinh doanh bất động sản niêm yết trên sở giao dịch chứng khoán Hà Nội và sở giao dịch chứng khoán Thành phố Hồ Chí Minh trong giai đoạn từ 2010 đến 2016 (67 x $7=469$ quan sát). Dữ liệu nghiên cứu được thu thập từ các báo cáo tài chính có kiểm toán được niêm yết tại website: www.vietstock.vn.

\subsection{Giả thuyết nghiên cúu}

Đòn bẩy tài chính: Lý thuyết tín hiệu đưa ra giả thuyết doanh nghiệp có sử dụng nhiều nợ thì nên sử dụng nợ dài hạn nhằm hạn chế rủi ro thanh khoản và giảm nguy cơ phá sản. Nghiên cứu thực nghiệm của Cai và cộng sự (2008), Lemma và Negash (2012) chứng minh rằng đòn bẩy tài chính tác động dương đến cấu trúc kỳ hạn nợ.

\section{$H_{1}$ : Đòn bẩy tài chính có mối tương quan duơng với cấu trúc kỳ hạn nơ}

Quy mô doanh nghiệp: Lý thuyết chi phí đại diện cho rằng những doanh nghiệp có quy mô nhỏ thường có tỷ lệ vay nợ cao và dễ phát sinh mâu thuẫn về lợi ích giữa cổ đông và người đại diện doanh nghiệp là rất lớn. Để giảm thiểu chi phí đại diện, doanh nghiệp nhỏ thường có khuynh hướng sử dụng khoản vay ngắn hạn, doanh nghiệp vay nhiều nợ để tạo cơ hội tăng trưởng trong tương lai sẽ sử dụng nhiều nợ dài hạn hơn (Cai et al., 2008; Deesomsak et al., 2009; Stephan et al., 2011). Ngoài ra, một số nghiên cứu thực nghiệm cho rằng các doanh nghiệp lớn có chi phí đại diện thấp hơn bởi vì họ có nhiều cơ hội tham gia vào thị trường vốn (Ozkan, 2002). 


\section{$H_{2}$ : Quy mô doanh nghiệp có mối quan hệ thuận chiều với cấu trúc kỳ hạn nợ}

Cơ cấu tài sản: Lý thuyết cân bằng, cơ cấu tài sản cố định của doanh nghiệp tỷ lệ thuận với cấu trúc vốn kỳ hạn nợ. Để giảm thiểu rủi ro và chi phí kiệt quệ tài chính, kỳ hạn của những khoản vay nợ phải phù hợp với kỳ hạn của tài sản trong doanh nghiệp. Những khoản vay dài hạn được sử dụng cho việc tài trợ các tài sản hữu hình, tài sản cố định của doanh nghiệp (Brick \& Ravid, 1985; Brick \& Ravid, 1991; Terra, 2011).

\section{$H_{3}$ : Co cấu tài sản có tuoong quan dương với cấu trúc kỳ hạn nọ}

Kỳ hạn tài sản: Nghiên cứu của Stohs và Mauer (1996) cho rằng kỳ hạn nợ thường ngắn hơn so với kỳ hạn tài sản do các doanh nghiệp không đủ tiền mặt để thanh toán các khoản nợ khi đến hạn. Ngược lại, nếu kỳ hạn nợ dài hơn kỳ hạn tài sản, các công ty sẽ đáp ứng các nghĩa vụ trả nợ các khoản vay. Chính vì vậy, kỳ hạn tài sản có quan hệ dương với cấu trúc kỳ hạn nợ và được đo bằng tỷ trọng của tài sản lưu động với giá vốn hàng bán cộng với tỷ trọng của tài sản cố định với giá trị khấu hao tài sản cố định. Nghiên cứu của Flannery (1986) và Diamond và Rajan (2001) lập luận rằng kỳ hạn tài sản có thể được sử dụng như là tín hiệu tốt để thực hiện các khoản vay ngắn hạn và dài hạn. Các doanh nghiệp phát tín hiệu tốt thông qua sự tín nhiệm tốt của cổ đông sẽ có khuynh hướng chọn các khoản vay ngắn hạn, còn các doanh nghiệp phát tín hiệu không tốt thông qua sự tín nhiệm thấp của cổ đông thường có khuynh hướng chọn khoản vay dài hạn do không đủ khả năng trả các khoản chi phí giao dịch (Terra, 2011).

\section{$H_{4}$ : Kỳ hạn tài sản có mối quan hệ đồng biến với cấu trúc kỳ hạn nợ}

Co hội tăng truởng: Nghiên cứu của Barclay và Smith (1995), Cai và cộng sự (2008), Lemma và Negash (2012) tìm thấy sự khác biệt về mối quan hệ giữa cấu trúc kỳ hạn nợ và cơ hội tăng trưởng ở các quốc gia khác nhau. Lý thuyết đại diện cho rằng mâu thuẫn giữa các cổ đông, nhà quản lý và các trái chủ trong doanh nghiệp có sử dụng nợ vay có thể làm giảm khả năng đầu tư vào những dự án có NPV dương vì lo ngại những lợi ích được đòi hỏi bởi các trái chủ, điều này sẽ dẫn đến việc đầu tư dưới mức, do vậy việc sử dụng nợ ngắn hạn được xem là giải pháp giảm mâu thuẫn về vấn đề đại diện.

\section{H5: Co hội tăng trưởng có mối tuơng quan nghịch với cấu trúc kỳ hạn nợ}

Tính thanh khoản: Lý thuyết tín hiệu cho rằng các doanh nghiệp có tính thanh khoản cao nên sử dụng nhiều nợ dài hạn nhằm giảm thiểu chi phí sử dụng vốn. Stohs và Mauer (1996), Cai và cộng sự (2008) cho rằng việc kiểm soát đòn bẩy tài chính khi có sự tác động của rủi ro thanh khoản đến thời gian đáo hạn nợ vì tính hiệu quả của quá trình giám sát các khoản vay phụ thuộc vào kết quả đánh giá doanh nghiệp vay nợ.

\section{H6: Tính thanh khoản có mối quan hệ cùng chiều với cấu trúc kỳ hạn nợ}

Thuế thu nhập doanh nghiệp: Lý thuyết về thuế cho rằng doanh nghiệp có sự đánh đổi giữa lợi ích từ lá chắn thuế và chi phí phá sản, chi phí phát hành. Vì vậy, kỳ hạn nợ có tương quan dương với chi phí phát hành và tương quan âm với lợi ích từ lá chắn thuế. Lợi ích từ lá chắn thuế do doanh nghiệp vay nợ dài hạn không phụ thuộc và giá trị nợ mà chủ yếu phụ thuộc vào các khoản được giảm trừ từ trích khấu hao tài sản hoặc các khoản lãi vay phải trả do đi vay nợ. Nghiên cứu của Cai và cộng sự (2008), Terra (2011) minh chứng lợi ích từ lá chắn thuế do doanh nghiệp sử dụng các khoản vay ngắn hạn. 


\section{H7: Thuế thu nhập doanh nghiệp có tương quan âm với cấu trúc kỳ hạn nợ}

Khả năng sinh lời: lý thuyết tín hiệu cho rằng cấu trúc kỳ hạn nợ có mối tương quan âm với khả năng sinh lời. Nghiên cứu của Deesomsak và cộng sự (2009); Terra (2011); Stephan và cộng sự (2011) cho rằng trong điều kiện bất cân xứng thông tin, việc đánh giá tín hiệu tốt của doanh nghiệp dựa trên việc vay nợ ngắn hạn. Vì vậy, khả năng sinh lời của các doanh nghiệp là rất quan trọng vì các doanh nghiệp có thể sử dụng các nguồn vốn khác nhau để tài trợ và dễ dàng tiếp cận các khoản vay nợ khi doanh nghiệp đạt được lợi nhuận tốt và phát tín hiệu tốt cho thị trường.

\section{H8: Khả năng sinh lời có quan hệ nghịch chiều với cấu trúc kỳ hạn nợ}

\section{Bảng 1}

Các yếu tố tác động đến cấu trúc kỳ hạn nợ

\begin{tabular}{|c|c|c|c|c|c|}
\hline $\begin{array}{c}\text { Ký } \\
\text { hiệu }\end{array}$ & Biến & Đo lường & $\begin{array}{c}\text { Kỳ } \\
\text { vọng }\end{array}$ & Lý thuyết & Nghiên cứu trước \\
\hline \multicolumn{6}{|c|}{ Biến phụ thuộc } \\
\hline DMR & $\begin{array}{l}\text { Cấu trúc kỳ } \\
\text { hạn nợ }\end{array}$ & $\begin{array}{l}\text { Nợ vay dài } \\
\text { hạn/(Nợ vay dài } \\
\text { hạn + Nợ ngắn } \\
\text { hạn) }\end{array}$ & & & $\begin{array}{l}\text { Barclay và Smith } \\
\text { (1995), Cai và cộng sự } \\
\text { (2008), Lemma và } \\
\text { Negash (2012). }\end{array}$ \\
\hline \multicolumn{6}{|c|}{ Biến độc lập } \\
\hline TDA & $\begin{array}{l}\text { Tỷ số nợ } \\
\text { trên tồng tài } \\
\text { sản }\end{array}$ & $\begin{array}{l}\text { Tổng nợ/Tổng tài } \\
\text { sản }\end{array}$ & $(+)$ & $\begin{array}{l}\text { Lý thuyết } \\
\text { tín hiệu }\end{array}$ & $\begin{array}{l}\text { Cai và cộng sự (2008); } \\
\text { Lemma và Negash } \\
\text { (2012). }\end{array}$ \\
\hline SIZE & $\begin{array}{l}\text { Quy mô } \\
\text { doanh } \\
\text { nghiệp }\end{array}$ & Log(Tổng tài sản) & (+) & $\begin{array}{l}\text { Lý thuyết } \\
\text { chi phí đại } \\
\text { diện }\end{array}$ & $\begin{array}{l}\text { Ozkan (2002); Cai và } \\
\text { cộng sự (2008); } \\
\text { Deesomsak và cộng sự } \\
\text { (2009); Stephan và } \\
\text { cộng sự (2011) }\end{array}$ \\
\hline TANG & $\begin{array}{l}\text { Cơ cấu tài } \\
\text { sản }\end{array}$ & $\begin{array}{l}\text { Tài sản cố định } \\
\text { hữu hình/Tồng tài } \\
\text { sản }\end{array}$ & (+) & $\begin{array}{l}\text { Lý thuyết } \\
\text { TOT }\end{array}$ & $\begin{array}{l}\text { Brick và Ravid (1985); } \\
\text { Brick và Ravid (1991); } \\
\text { Terra (2011) }\end{array}$ \\
\hline AMR & $\begin{array}{l}\text { Kỳ hạn tài } \\
\text { sản }\end{array}$ & $\begin{array}{l}\text { (Tài sản lưu } \\
\text { động/Giá vốn hàng } \\
\text { bán) + (Tài sản cố } \\
\text { định/khấu hao) }\end{array}$ & $(+)$ & $\begin{array}{l}\text { Lý thuyết } \\
\text { tín hiệu }\end{array}$ & $\begin{array}{l}\text { Stohs và Mauer (1996); } \\
\text { Flannery (1986); } \\
\text { Diamond và Rajan } \\
\text { (2001); } \\
\text { Terra (2011). }\end{array}$ \\
\hline $\begin{array}{l}\text { GRO } \\
\mathrm{W}\end{array}$ & $\begin{array}{l}\text { Cơ hội tăng } \\
\text { trưởng }\end{array}$ & $\begin{array}{l}\text { (Tổng tài sản }{ }_{i, t}- \\
\text { Tổng tài sản }{ }_{i, t-1} \text { )/ } \\
\text { Tổng tài sản }{ }^{1, t-1}\end{array}$ & $(+/-)$ & $\begin{array}{l}\text { Lý thuyết } \\
\text { chi phí đại } \\
\text { diện }\end{array}$ & $\begin{array}{l}\text { Barclay và Smith } \\
\text { (1995); Cai và cộng sự } \\
\text { (2008); Lemma và } \\
\text { Negash (2012) }\end{array}$ \\
\hline LIQV & $\begin{array}{l}\text { Tính thanh } \\
\text { khoản }\end{array}$ & $\begin{array}{l}\text { Tài sản ngắn } \\
\text { hạn/Nợ ngắn hạn }\end{array}$ & (+) & $\begin{array}{l}\text { Lý thuyết } \\
\text { tín hiệu }\end{array}$ & Cai và cộng sự (2008) \\
\hline
\end{tabular}




\begin{tabular}{|c|l|l|c|l|l|}
\hline $\begin{array}{c}\text { Ký } \\
\text { hiệu }\end{array}$ & \multicolumn{1}{|c|}{ Biến } & \multicolumn{1}{c|}{ Đo lường } & $\begin{array}{c}\text { Kỳ } \\
\text { vọng }\end{array}$ & Lý thuyết & \multicolumn{1}{|c|}{ Nghiên cứu trước } \\
\hline TAX & $\begin{array}{l}\text { Thuế thu } \\
\text { nhập doanh } \\
\text { nghiệp }\end{array}$ & $\begin{array}{l}\text { Thuế thu nhập } \\
\text { doanh nghiệp/Lợi } \\
\text { nhuận trước thuế }\end{array}$ & $(-)$ & $\begin{array}{l}\text { Lý thuyết } \\
\text { về thuế }\end{array}$ & $\begin{array}{l}\text { Cai và cộng sự (2008); } \\
\text { Terra (2011). }\end{array}$ \\
\hline PROF & $\begin{array}{l}\text { Khả năng } \\
\text { sinh lời }\end{array}$ & EBIT/Tổng tài sản & $(-)$ & $\begin{array}{l}\text { Lý thuyết } \\
\text { tín hiệu }\end{array}$ & $\begin{array}{l}\text { Deesomsak và cộng sự } \\
\text { (2009); Terra (2011); } \\
\text { Stephan và cộng sự } \\
(2011) .\end{array}$ \\
\hline
\end{tabular}

Nguồn: Tác giả tổng hợp

\subsection{Mô hình nghiên cúu}

Nghiên cứu này sử dụng mô hình kỳ hạn nợ của Brick và Ravid (1985), Stohs và Mauer (1996) và Stephan và cộng sự (2011) để tìm các nhân tố ảnh hưởng cấu trúc kỳ hạn nợ của các doanh nghiệp kinh doanh bất động sản niêm yết trên thị trường chứng khoán Việt Nam.

Mô hình nghiên cứu:

$$
\mathrm{DMR}_{\mathrm{i}, \mathrm{t}}=\alpha_{\mathrm{i}}+X_{i, t}^{\prime} \beta+\mathrm{u}_{\mathrm{i}, \mathrm{t}}
$$

Trong đó:

- $\mathrm{DMR}_{\mathrm{i}, \mathrm{t}}$ là biến phụ thuộc đại diện cho cấu trúc kỳ hạn nợ;

- $\quad X_{i, t}$ là các biến độc lập đại diện cho các nhân tố ảnh hưởng đến cấu trúc kỳ hạn nợ, gồm đòn bẩy tài chính (TDA); quy mô doanh nghiệp (SIZE); cơ cấu tài sản (TANG); kỳ hạn tài sản (AMR); cơ hội tăng trưởng (GROW); khả năng thanh toán ngắn hạn (LIQV); Thuế thu nhập doanh nghiệp (TAX), lợi nhuận (PROF);

- $\quad \alpha_{i}$ là tác động riêng lẻ của doanh nghiệp thứ I;

- $\mathrm{u}_{\mathrm{i}, \mathrm{t}}$ là sai số;

- $\beta$ là hệ số chặn;

- i là số doanh nghiệp trong mẫu nghiên cứu;

- $\mathrm{t}$ là số năm nghiên cứu.

\subsection{Phương pháp nghiên cúu}

Bài nghiên cứu này sẽ thực hiện hồi quy mô hình (1) theo mô hình Pooled OLS, mô hình ảnh hưởng cố định (FEM) và mô hình ảnh hưởng ngẫu nhiên (REM) để lựa chọn mô hình nghiên cứu phù hợp trên cơ sở sử dụng các kiểm định F-test, Wald, Breusch - Pagan, Hausman.

Dựa trên kết quả kiểm định lựa chọn mô hình để phát hiện các hệ số hồi quy bị sai lệch, có khả năng có hiện tượng phương sai thay đổi và hiện tượng tự tương quan dẫn đến kết quả ước lượng không còn hiệu quả. Nghiên cứu sẽ thực hiện kiểm định Wooldright để kiểm định tự tương quan và kiểm định Breusch - Pagan để kiểm định phương sai thay đổi. Tuy nhiên, các mô hình Pooled OLS, FEM và REM không thể khắc phục được hiện tượng nội sinh. Theo Blundell và Bond (1998) cho rằng mô hình GMM hệ thống (Sys-GMM) sẽ khắc phục tốt nhất hiện tượng tự tương quan, phương sai thay đổi và hiện tượng nội sinh trong việc lựa chọn mô hình FEM và REM. 


\section{Kết quả nghiên cứu}

\subsection{Thống kê mô tả}

Kết quả thống kê mô tả thể hiện ở Bảng 2 cho thấy kỳ hạn nợ trung bình của các doanh nghiệp kinh doanh bất động sản trong giai đoạn nghiên cứu đạt $30,8 \%$, độ lệch chuẩn cho thấy biến động nợ dài hạn so với trung bình đạt 24,73\% - thấp hơn giá trị trung bình. Điều này cho thấy đa số các khoản đi vay của doanh nghiệp là các khoản vay ngắn hạn và chủ yếu từ nguồn tài trợ của ngân hàng. Bên cạnh đó, giá trị thấp nhất của cấu trúc kỳ hạn nợ là 0 - cho thấy có những doanh nghiệp không sử dụng nợ dài hạn, giá trị cao nhất 0,958 nghĩa là doanh nghiệp sử dụng 95,8\% nợ dài hạn trong cơ cấu nợ của doanh nghiệp.

\section{Bảng 2}

Kết quả thống kê mô tả các biến

\begin{tabular}{lccccc}
\hline \multicolumn{1}{c}{ Tên biến } & $\begin{array}{c}\text { Số quan } \\
\text { sát }\end{array}$ & $\begin{array}{c}\text { Giá trị trung } \\
\text { bình }\end{array}$ & $\begin{array}{c}\text { Độ lệch } \\
\text { chuẩn }\end{array}$ & $\begin{array}{c}\text { Giá trị nhỏ } \\
\text { nhất }\end{array}$ & $\begin{array}{c}\text { Giá trị lớn } \\
\text { nhất }\end{array}$ \\
\hline DMR & 469 & 0,308 & 0,247 & 0 & 0,958 \\
TDA & 469 & 0,519 & 0,193 & 0,011 & 0,926 \\
SIZE & 469 & 14,109 & 1,394 & 9,966 & 19,011 \\
TANG & 469 & 0,381 & 0,244 & 0 & 0,934 \\
GROW & 469 & 0,866 & 10,199 & $-0,993$ & 208,924 \\
LIQV & 469 & 2,441 & 2,262 & 0,233 & 23,211 \\
TAX & 469 & 0,148 & 1,142 & -23.827 & 3,433 \\
PROF & 469 & 0,029 & 0,074 & $-0,488$ & 0,407 \\
AMR & 469 & 14,527 & 58,795 & 0,025 & $1.002,215$ \\
\hline
\end{tabular}

Nguồn: Tác giả truy xuất kết quả từ phần mềm Stata

\subsection{Ma trận hệ số tuơng quan}

\section{Bảng 3}

Ma trận hệ số tương quan giữa các biến

\begin{tabular}{lrrrrrrrrr}
\hline & \multicolumn{1}{c}{ DMR } & \multicolumn{1}{c}{ TDA } & SIZE & TANG & GROW & LIQV & TAX & PROF & AMR \\
\hline DMR & 1 & & & & & & & & \\
TDA & 0,1987 & 1 & & & & & & & \\
SIZE & 0,3466 & 0,3039 & 1 & & & & & & \\
TANG & 0,0534 & 0,2642 & 0,1742 & 1 & & & & & \\
GROW & 0,0005 & 0,0111 & 0,0925 & $-0,0678$ & 1 & & & & \\
LIQV & 0,4957 & $-0,2845$ & $-0,0388$ & 0,1147 & $-0,0444$ & 1 & & & \\
TAX & $-0,0025$ & 0,0708 & 0,0123 & 0,0027 & 0,0071 & $-0,0243$ & 1 & & \\
PROF & $-0,0398$ & $-0,1348$ & $-0,0594$ & $-0,0012$ & 0,0892 & 0,1310 & 0,0450 & 1 &
\end{tabular}




\begin{tabular}{lccccccccr}
\hline & DMR & TDA & SIZE & TANG & GROW & LIQV & TAX & PROF & AMR \\
\hline AMR & 0,0620 & 0,0070 & 0,0579 & 0,0007 & $-0,0156$ & 0,0251 & 0,0078 & $-0,0571$ & 1 \\
\hline VIF* & & 1,32 & 1,15 & 1,14 & 1,13 & 1,05 & 1,03 & 1,01 & 1,01 \\
\hline
\end{tabular}

VIF*: Variance Inflation Factor

Nguồn: Tác giả truy xuất kết quả từ phần mềm Stata

Kết quả ở Bảng 3 cho thấy, cấu trúc kỳ hạn nợ (DMR) có tương quan cao nhất với biến tính thanh khoản (LIQV) với hệ số tương quan là $49,57 \%$ và có tương quan thấp dưới $1 \%$ với biến cơ hội tăng trưởng (GROW), thuế thu nhập doanh nghiệp (TAX). Dấu của các biến phụ thuộc và biến độc lập đều phù hợp với kỳ vọng giả thuyết, ngoại trừ biến cơ hội tăng trưởng (GROW).

Kết quả kiểm tra hiện tượng đa cộng tuyến (VIF) giữa các biến độc lập trong mô hình đều có giá trị nhỏ hơn 10, như vậy không có xảy ra hiện tượng đa cộng tuyến giữa các biến.

\subsection{Phân tích kết quả hồi quy}

Kết quả hồi quy các yếu tố tác động đến cấu trúc kỳ hạn nợ của 67 doanh nghiệp kinh doanh bất động sản tại Việt Nam được trình bày trong Bảng 4 với các phương pháp ước lượng Pooled OLS, FEM, REM và Sys-GMM. Kiểm định F-test cho mô hình Pooled OLS và FEM cho thấy các mô hình đều ước lượng phù hợp với mức ý nghĩa $1 \%$. Kiểm định $\mathrm{W}$ ald cho mô hình REM và mô hình Sys-GMM cũng cho kết quả ước lượng với mức ý nghĩa $1 \%$, nghĩa là mô hình ước lượng là phù hợp.

\section{Bảng 4}

Kết quả hồi quy các yếu tố tác động đến cấu trúc kỳ hạn nợ

\begin{tabular}{|l|c|c|c|c|}
\hline \multirow{2}{*}{ TDA } & Pooled OLS & FEM & REM & Sys-GMM \\
\hline \multirow{2}{*}{ SIZE } & $0,409^{* * *}$ & $0,295^{* * *}$ & $0,335^{* * *}$ & $0,207 * *$ \\
\cline { 2 - 5 } & {$[0,000]$} & {$[0,000]$} & {$[0,000]$} & {$[0,003]$} \\
\hline \multirow{2}{*}{ TANG } & $0,0526^{* * *}$ & $0,0655^{* *}$ & $0,0571^{* * *}$ & $0,0295^{* *}$ \\
\cline { 2 - 5 } & {$[0,000]$} & {$[0,001]$} & {$[0,000]$} & {$[0,001]$} \\
\hline \multirow{2}{*}{ GROW } & $-0,157^{* * *}$ & $-0,177^{* * *}$ & $-0,173^{* * *}$ & $-0,138^{* * *}$ \\
\cline { 2 - 5 } & {$[0,000]$} & {$[0,000]$} & {$[0,000]$} & {$[0,000]$} \\
\hline \multirow{2}{*}{ LIQV } & $-0,0001$ & 0,0001 & 0,0001 & 0,161 \\
\cline { 2 - 5 } & {$[0,824]$} & {$[0,899]$} & {$[0,920]$} & {$[0,349]$} \\
\hline \multirow{2}{*}{ TAX } & $0,0680 * * *$ & $0,0379^{* * *}$ & $0,0445^{* * *}$ & $0,0388^{* * *}$ \\
\cline { 2 - 5 } & {$[0,000]$} & {$[0,000]$} & {$[0,000]$} & {$[0,000]$} \\
\hline \multirow{2}{*}{ PROF } & $-0,0023$ & 0,00608 & 0,00452 & 0,00893 \\
\cline { 2 - 5 } & {$[0,752]$} & {$[0,235]$} & {$[0,378]$} & {$[0,177]$} \\
\hline AMR & $-0,196$ & $-0,155$ & $-0,144$ & $-0,355^{*}$ \\
\cline { 2 - 5 } & {$[0,094]$} & {$[0,092]$} & {$[0,111]$} & {$[0,039]$} \\
\hline
\end{tabular}




\begin{tabular}{|c|c|c|c|c|}
\hline & Pooled OLS & FEM & REM & Sys-GMM \\
\hline & {$[0,486]$} & {$[0,902]$} & {$[0,844]$} & {$[0,004]$} \\
\hline \multirow{2}{*}{ Hệ số chặn } & $-0,748 * * *$ & $-0,791 * *$ & $-0,712 * * *$ & $-0,363 * *$ \\
\hline & {$[0,000]$} & {$[0,004]$} & {$[0.000]$} & [0.007] \\
\hline Số quan sát & 469 & 469 & 469 & 469 \\
\hline F-test & $51,03 * * *$ & $14,40 * * *$ & & \\
\hline Wald & & & $179,43 * * *$ & $419,32 * * *$ \\
\hline Breusch Pagan (LM) & $104,31 * * *$ & $21.080,8 * * *$ & $407,28 * * *$ & \\
\hline Hausman & & $26,17 * * *$ & & \\
\hline Wooldright & & $39,081 * * *$ & & \\
\hline AR2 & & & & $\begin{array}{c}0,73 \\
{[0,462]}\end{array}$ \\
\hline Sargan & & & & $\begin{array}{c}6,88 \\
{[0,442]}\end{array}$ \\
\hline
\end{tabular}

*,**,*** có các mức ý nghĩa thống kê lần lượt là $10 \%, 5 \%$ và $1 \%$; [ ] là giá trị p-value Nguồn: Tác giả truy xuất kết quả từ phần mềm Stata

Để thực hiện lựa chọn mô hình phù hợp, sử dụng kiểm định LM để lựa chọn mô hình Pooled OLS và mô hình REM, kết quả kiểm định cho thấy p-value nhỏ hơn $5 \%$, nghĩa là mô hình REM là phù hợp. Kiểm định Hausman để lựa chọn mô hình REM và mô hình FEM, kết quả kiểm định giá trị p-value nhỏ hơn $5 \%$, điều này cho thấy lựa chọn mô hình FEM là phù hợp. Như vậy, việc lựa chọn giữa mô hình REM và mô hình FEM thì mô hình FEM được cho là phương pháp phù hợp nhất. Tuy nhiên, kết quả kiểm định $L M$ và Wooldright đều cho thấy mô hình REM và mô hình FEM đều tồn tại hiện tượng phương sai thay đổi và tự tương quan, điều này sẽ làm cho các hệ số hồi quy ước lượng không còn hiệu quả. Theo Blundell và Bond (1998), để khắc phục các nhược điểm của mô hình FEM và REM cần phải sử dụng mô hình Sys-GMM ước lượng mô hình (1). Đây là phương pháp phù hợp nhất sẽ giúp loại bỏ vấn đề phương sai thay đổi, tự tương quan hay nội sinh nên kết quả ước lượng sẽ hiệu quả.

Kết quả thực hiện ước lượng bằng phương pháp Sys-GMM cho thấy mô hình có ý nghĩa thống kê, các kết quả kiểm định phương sai thay đổi, tự tương quan đều được khắc phục, giá trị p-value của $A R 2=0,462>0,05$. Kiểm định Sargan cho thấy mô hình Sys-GMM phù hợp thể hiện giá trị $\mathrm{p}$-value $=0,442>0,05$.

Kết quả nghiên cứu phù hợp với lý thuyết chi phí đại diện cho rằng cơ hội tăng trưởng có tác động dương đến kỳ hạn nợ của doanh nghiệp và phù hợp với nghiên cứu của Barclay và Smith (1995); Cai và cộng sự (2008). Tuy nhiên, yếu tố này lại không có ý nghĩa thống kê. Điều này nghĩa là do đặc thù của các doanh nghiệp kinh doanh bất động sản, khi thị trường phát tín hiệu tốt, các doanh nghiệp sẽ tập trung nỗ lực đầu tư thậm chí đầu tư quá mức và ngược lại khi thị trường phát tính hiệu xấu, các doanh nghiệp sẽ giảm đầu tư. Kết quả nghiên cứu cho thấy ở giai đoạn này các doanh nghiệp kinh doanh bất động sản đang ở trạng thái đầu tư quá mức ở trước thời kỳ suy thoái nền kinh tế, do vậy ở giai đoạn này hầu như không tiến hành đầu tư thêm nữa mà tận dụng lợi thế hiện tại để hoạt động, vì vậy yếu tố này không có ý nghĩa gì về 
mặt thống kê. Bên cạnh đó, thuế thu nhập doanh nghiệp không có ý nghĩa thống kê do các doanh nghiệp kinh doanh bất động sản được hưởng các khoản thuế ưu đãi nếu như doanh nghiệp đầu tư xây dựng các dự án nhà ở xã hội, chính điều này trong mẫu dữ liệu thu thập thì thuế thu nhập doanh nghiệp của một số doanh nghiệp đạt giá trị 0 đồng và được khấu trừ, hoàn thuế cho doanh nghiệp. Kết quả này tương đồng với nghiên cứu của Lemma và Negash (2012).

Đồng thời kết quả nghiên cứu cũng phản ánh thực trạng sử dụng đòn bẩy tài chính của các doanh nghiệp kinh doanh bất động sản tại Việt Nam, yếu tố tài sản hữu hình và đòn bẩy tài chính đều tác động đến kỳ hạn nợ và có ý nghĩa dưới $5 \%$. Điều này, chứng tỏ các doanh nghiệp kinh doanh bất động sản rất quan tâm đến sự phù hợp của kỳ hạn nợ và kỳ hạn của tài sản để đưa ra quyết định vay nợ cho phù hợp vì đa phần các dự án của doanh nghiệp đều là những dự án có quy mô lớn, đòi hỏi nguồn vốn lớn, cũng chính vì điều này làm cho yếu tố cấu trúc tài sản hữu hình và kỳ hạn tài sản quan hệ nghịch chiều với cấu trúc kỳ hạn nợ, phù hợp với nghiên cứu của Lemma và Negash (2012).

\section{Kết luận và hàm ý các chính sách}

Bài nghiên cứu kiểm định mô hình Sys-GMM trên số liệu 67 doanh nghiệp kinh doanh bất động sản niêm yết trên sở giao dịch chứng khoán Hà Nội và sở giao dịch chứng khoán Thành phố Hồ Chí Minh cung cấp bằng chứng ủng hộ lý thuyết cân bằng, lý thuyết chi phí đại diện, lý thuyết tín hiệu và lý thuyết về thuế. Kết quả nghiên cứu cho thấy tỷ lệ nợ, quy mô doanh nghiệp, cơ cấu tài sản, lợi nhuận, kỳ hạn nợ có tác động đến cấu trúc kỳ hạn nợ của doanh nghiệp, còn cơ hội tăng trưởng, thuế thu thập doanh nghiệp không có tác động đến cấu trúc kỳ hạn nợ.

Hạn chế của bài nghiên cứu này là chưa xem xét các yếu tố vĩ mô có tác động đến cấu trúc kỳ hạn nợ của doanh nghiệp cũng như phạm vi nghiên cứu và mẫu nghiên cứu còn giới hạn. Tuy nhiên, hạn chế của nghiên cứu sẽ là cơ hội cho những nghiên cứu tiếp theo.

Từ kết quả phân tích trên, tác giả đề xuất một số khuyến nghị cho các doanh nghiệp kinh doanh bất động sản niêm yết trên thị trường chứng khoán Việt Nam như sau:

Thư nhất, đối với các nhà quản trị doanh nghiệp. Kết quả nghiên cứu cung cấp bằng chứng hơn $90 \%$ doanh nghiệp kinh doanh bất động sản có vay nợ ngắn hạn và nợ dài hạn để tài trợ các dự án doanh nghiệp triển khai kinh doanh. Tuy nhiên, doanh nghiệp kinh doanh bất động sản cần xem xét đặc điểm của doanh nghiệp mình để thực hiện chính sách kỳ hạn nợ hợp lý bởi sự điều chỉnh trong cấu trúc kỳ hạn nợ chậm sẽ làm gia tăng chi phí đại diện. Mặt khác, khi xây dựng cấu trúc kỳ hạn nợ, doanh nghiệp cần quan tâm đến giá trị tài sản hiện tại, tỷ lệ nợ, tính thanh khoản. Đây chính là những yếu tố thể hiện tình trạng sức khỏe của doanh nghiệp. Nếu doanh nghiệp có tín hiệu tốt thể hiện năng lực tài chính, khả năng thanh khoản, khả năng sinh lời tốt thì sẽ quyết định chọn kỳ hạn nợ dài hạn, ngược lại doanh nghiệp phát tín hiệu về tình hình tài chính không tốt sẽ có ưu tiên lựa chọn kỳ hạn nợ ngắn hạn.

Thư hai, đối với các tổ chức tín dụng. Trong quy trình cho vay của các tổ chức tín dụng, tiêu chí bắt buộc để giải quyết nhu cầu cho vay chính là yếu tố tài sản hữu hình làm tài sản đảm bảo cho các khoản vay. Vì vậy, việc các tổ chức tín dụng định giá trị các tài sản này như thế nào vừa đảm bảo rủi ro cho các tổ chức tín dụng, vừa bảo đảm quyền lợi cho các doanh nghiệp sở hữu tài sản đảm bảo cho các khoản vay của mình. Mặt khác, đa số tài sản hữu hình của các 
doanh nghiệp kinh doanh bất động sản là đất đai, các căn hộ hình thành trong tương lai, việc định giá trị của các tài sản đất đai, các căn hộ hình thành trong tương lai phải tuân thủ theo quy định của Luật đất đai, Luật kinh doanh bất động sản.

\section{Tài liệu tham khảo}

Barclay, M. J., \& Smith. C. W. (1995). The maturity structure of corporate debt. The Journal of Finance, 50(2), 609-631.

Barnea, A, Haugen, R. A., \& Senbet, L. W. (1980). A rationale for debt maturity structure and call provisions in the agency theoretic framework. Journal of Finance, 35, 1223-1234.

Blundell, R. W., \& Bond S. R. (1998). Initial conditions and moment restrictions in dynamic panel data models. Journal of Econometrics, 87, 115-143.

Brick, I. E., \& Ravid, S. A. (1985). On the relevance of debt maturity structure. Journal of Finance, 40(5), 1423-1437.

Brick, I. E., \& Ravid, S. A. (1991). Interest rate uncertainty and the optimal debt maturity structure. Journal of Financial and Quantitative Analysis, 26(1), 63-81.

Cai, K., Fairchild, R., \& Guney, Y. (2008). Debt maturity structure of Chinese companies. Pacific-Basin Finance Journal, 16(3), 268-297.

Deesomsak, R., Paudyal, K., \& Pescetto, G. (2009). Debt maturity structure and the 1997 Asian financial crisis. Journal of Multinational Financial Management, 19, 312-324.

Demirgüç-Kunt, A., \& Vojislav, M. (1999). Institutions, financial markets and firm debt maturity. Journal of Financial Economics, 54, 295-336.

Diamond, D. W., \& Rajan, R. (2001). Banks, short term debt, and financial crises: Theory, policy implications, and applications. Proceedings of Carnegie Rochester Series on Public Policy, 54, 37-71.

Flannery, M. J. (1986). Asymmetric information and risky debt maturity choice. Journal of Finance, 41, 19-37.

Jensen, M. C., \& Meckling, W. H. (1976). Theory of the firm: Managerial behavior, agency cost and ownership structure. Journal of Financial Economics, 3, 305-360.

Jun, S. G., \& Jen, F. C. (2003). Trade-off model of debt maturity structure. Review of Quantitative Finance and Accounting, 20, 5-34.

Lemma, T. T., \& Negash, M. (2012). Debt maturity choice of a firm: Evidence from African countries. Journal of Business and Policy Research, 7(2), 60-92.

Lewis, C. M. (1990). A multi-period theory of corporate financial policy under taxation. Journal of Financial and Quantitative Analysis, 25, 25-44.

Myers, S. C. (1977). Determinants of corporate borrowing. Journal of Financial Economics, 5, 146-176. 
Myers, S. C., \& Majluf, N. (1984). Corporate financing and investment decisions when firms have information that investors do not have. The Journal of Finance Economics, 13, 187221.

Ozkan, A. (2002). The determininants of corporate debt maturity structure: Evidence from UK firms. Applied Financial Economics, 12, 19-24.

Stephan, A., Talavera, O., \& Tsapin, A. (2011). Corporate debt maturity choice in emerging financial markets. Quarterly Review of Economics and Finance, 51, 141-151.

Stohs, M. H., \& Mauer, D. C. (1996). The determinants of corporate debt maturity structure. Journal of Business, 69, 279-312.

Terra, P. R. S. (2011). Determinants of corporate debt maturity in Latin America. European Business Review, 23(1), 45-70. 